\title{
Rigid video laparoscope: a low-cost alternative to traditional diagnostic laparoscopy and laparoscopic surgery
}

\author{
Sagar Jawale', Gnanaraj Jesudian², Prakash Agarwal ${ }^{3}$ \\ 'Jawale Institute of pediatric surgery, Jilha Peth, Gandhi Nagar, Jalgaon 425001, Maharashtra, India. \\ ${ }^{2}$ Karunya Institute of Science and Technology, Coimbatore 641114, Tamil Nadu, India. \\ ${ }^{3}$ Professor \& Head of Pediatric Surgery at the Sri Ramachandra Medical College, Chennai- 600116 and Consultant Pediatric \\ Surgeon at The Apollo hospital, Chennai 600006, Tamil Nadu, India.
}

Correspondence to: Dr. Sagar Jawale, Jawale Institute of pediatric surgery, Jilha Peth, Gandhi Nagar, Jalgaon 425001, Maharashtra, India. E-mail: drsagarjawale@gmail.com

How to cite this article: Jawale S, Jesudian G, Agarwal P. Rigid video laparoscope: a low- cost alternative to traditional diagnostic laparoscopy and laparoscopic surgery. Mini-invasive Surg 2019;3:19. http://dx.doi.org/10.20517/2574-1225.2019.12

Received: 18 Apr 2019 First Decision: 24 Apr 2019 Revised: 24 Apr 2019 Accepted: 15 May 2019 Published: 26 Jun 2019

Science Editor: Giulio Belli Copy Editor: Cai-Hong Wang Production Editor: Jing Yu

\section{INTRODUCTION}

Diagnosis of abdominal conditions is always a challenge in rural areas. The modern diagnostic facilities like CT scans and MRI are not available there. Survey of the operation registers of many rural hospitals (17 hospitals) belonging to an association of hospitals in North India revealed that Diagnostic laparotomies were a common surgical procedure in rural areas ${ }^{[1]}$. Despite the high costs and invasive nature Laparotomies were still carried out in rural areas because of the cost effectiveness and convenience. Society of American Gastrointestinal and Endoscopic Surgeons (SAGES) have given a long list of indications for Diagnostic laparoscopy that are applicable in Urban areas too ${ }^{[2]}$.

The problem in rural areas is the high costs involved in the set up for Diagnostic Laparoscopies. Traditionally it would involve almost all the equipment required for laparoscopic surgeries and most of the rural surgical facilities cannot afford such high costs especially if they are doing only diagnostic laparoscopies. We offer an alternative low- cost method for carrying out Diagnostic Laparoscopies. The second author has used this innovation for diagnostic laparoscopies in rural areas. This innovation, a unique rigid video laparoscope is the first device of its kind described in the literature of laparoscopy. A patent is filed for it at Mumbai office.

\footnotetext{
(C) $(1)$

(C) The Author(s) 2019. Open Access This article is licensed under a Creative Commons Attribution 4.0 International License (https://creativecommons.org/licenses/by/4.0/), which permits unrestricted use, sharing, adaptation, distribution and reproduction in any medium or format, for any purpose, even commercially, as long as you give appropriate credit to the original author(s) and the source, provide a link to the Creative Commons license, and indicate if changes were made.
}

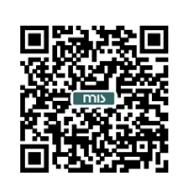




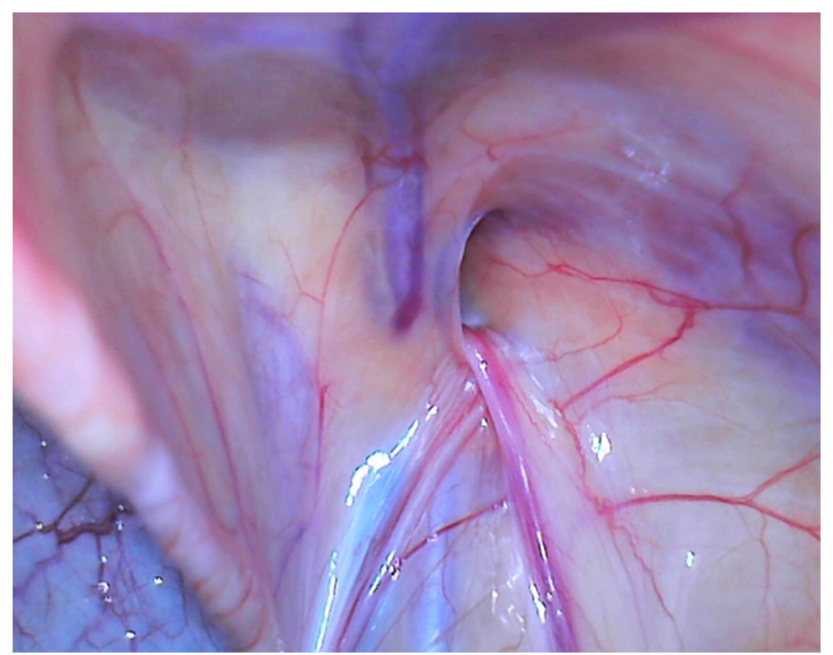

Figure 1. shows that the picture quality is excellent

\section{Rigid Video Laparoscope}

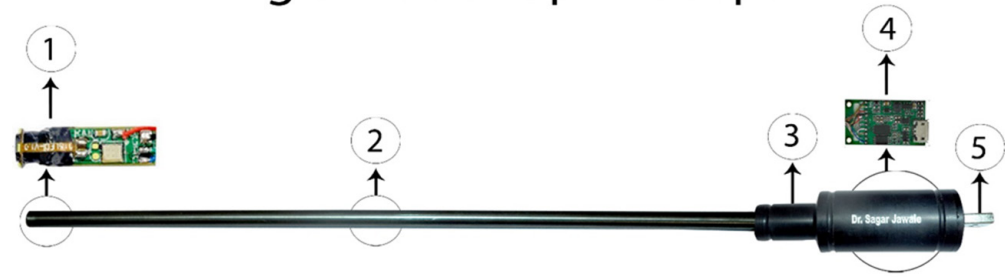

1. Video camera

2. Stainless steel tube
3. Handle of Poly acetal (Delrin)

4. Analogue to digital converter

\section{USB male connector}

Figure 2. shows the various parts of the innovative Laparoscope

\section{MATERIALS AND METHODS}

The first author has used these laparoscopes in his hospital from last 5 years for laparoscopy in children and adults in about 356 cases and got away completely with the conventional equipment. It has been used for laparoscopic surgeries such as appendicectomy, orchidopexies [Supplementary Video 1-2], herniotomies [Supplementary Video 3], pyloromyotomy, Intussusception reduction and in diagnostic laparoscopies.

Diagnostic Laparoscopies are carried out using our innovative equipment that has the video camera and LED lights in the tip of the instrument. It is connected to the Laptop computer through a USB hub and is powered by the Laptop computer. It makes the rod lens system and the light source redundant. Since there is no image loss by the rod lenses, the image quality is phenomenal [Figure 1].

These scopes are available in 5, 8 - and 10 - $\mathrm{mm}$ sizes. The camera is fitted at the tip of a seamless joint free stainless-steel tube with $5 \mathrm{~mm}, 8 \mathrm{~mm}$ and $10 \mathrm{~mm}$ diameter [Figure 2]. The wires of the camera are connected to male USB connector which is fitted outside the holder of the scope. The holder of the scope is made up of heat resistant polymer called Delrin (Polyacetal). Polyacetal or polyformaldehyde, is an engineering thermoplastic used in precision parts requiring high stiffness, low friction, and excellent dimensional stability. The focal length is from 2 to $20 \mathrm{~cm}$ and the white balance, shutter, iris, colors are automatically set by the camera. 
Specification of the camera used are: Sensor: $1 / 12$ color COMS, Pixel size: $1.75 \mu \mathrm{m} \times 1.75 \mu \mathrm{m}$, Effective Pixels: $1080(\mathrm{~h}) \times 800(\mathrm{v})$, Operation Temperature: $-10{ }^{\circ} \mathrm{C} \sim+50{ }^{\circ} \mathrm{C}, \mathrm{S} / \mathrm{N}$ Ratio: $38 \mathrm{~dB}$

LED:6PCS 0402 LED, DC3.3 V $\times 50 \mathrm{~mA}$, Dimensions $7 \mathrm{~mm} \times 20 \mathrm{~mm}$, Image Sensor: $1440 \mu \mathrm{m} \times 1653 \mu \mathrm{m}$, Fps: 30 Fps constant, Sensitivity: $960 \mathrm{mV}$ (Lux $\times \mathrm{sec}$ ), Voltage: 5 volts DC, Video Output: USB, Dynamic range: $66 \mathrm{~dB}$, FOV: 90 degrees, DOF: $2-5 \mathrm{~cm}$

\section{DISCUSSION}

The need for diagnostic laparoscopic surgeries in rural areas brought many innovations. For example the use of Gas Insufflation Less Laparoscopic Surgeries (GILLS) ${ }^{[2]}$ and the use of cystoscope for laparoscopy in rural areas ${ }^{[1]}$. This would still require the Laparoscopic camera and the light source. The rigid Laparoscope is a three in one device replacing the telescope, light source and camera combining them into a single lowcost device.

The advent of Laparoscopy has widened the need for Diagnostic laparoscopies especially in gynecological practice like confirming the diagnosis of acute pelvic inflammatory disease; in the evaluation of malignancies and abdominal-pelvic trauma; and the surgical treatment of pelvic pain ${ }^{[2]}$.

Since the laparoscope has a video camera in the front, the image is converted into electronic signal and there is no image loss as in the case of rod lenses of conventional optical laparoscopes. Hence the video quality is excellent [Supplementary Video 4-5]. The video quality was excellent for variety of operations such as needle assisted laparoscopic herniotomy [Supplementary Video 3], Laparoscope assisted orchidopexies [Supplementary Video 1-2], etc. The laparoscope is a three in one device in the sense that It is the combination of a telescope, Led light source and laparoscopic endo camera. It is equivalent to $\$ 10,000$ as $\$ 4000$ for optical endoscope, $\$ 4000$ for endo camera and $\$ 2000$ for Led light source are incorporated in it. With great hard work the first author himself commercialized it with a cost of $\$ 300$ which is the cheapest laparoscope in the market today. It is being distributed in India and world over through a no profit organization called Vigyan Yog Foundation founded by the author.

\section{CONCLUSION}

The rigid video laparoscope device is safe, compact of good quality and is likely to revolutionize diagnostic and operative laparoscopy in India and other third world countries.

\section{DECLARATIONS}

\section{Authors' contributions}

Devised the manuscript and did the clinical study: Jawale S

Used the device for diagnostic laparoscopies in rural areas: Jesudian $\mathrm{G}$

Helped raising the manuscript: Agarwal P

\section{Availability of data and materials}

Not applicable.

\section{Financial support and sponsorship}

The first author have done the whole research and study with his own money.

\section{Conflicts of interest}

All authors declared there are no conflicts of interest. 


\section{Ethical approval and consent to participate}

Not applicable.

\section{Consent for publication}

Not applicable.

\section{Copyright}

(C) The Author(s) 2019.

\section{REFERENCES}

1. J. Gnanaraj. Diagnostic laparoscopies in rural areas:a different use for cystoscope tropical doctor 40: 3 July 2010 p 156. Available from: https://www.sages.org/publications/guidelines/guidelines-for-diagnostic-laparoscopy. [Last accessed on 22 May 2019]

2. Loffer FD, Pent D. Indications, contraindications and complications of diagnostic laparoscopies. Obstet Gynecol Surg 1975;30:407-27. Available from: http://mdcurrent.in/primary-care/low-cost-laparoscopic-surgeries-taking-modern-surgery-poor. [Last accessed on 22 May 2019] 